\title{
Racialisation and the micro-ecology of contact
}

\author{
Don Foster \\ University of Cape Town, Private Bag, Rondebosch, 7701, South Africa \\ e-mail: foster@humanities.uct.ac.za
}

\begin{abstract}
This article reviews and comments on the six articles presented in the special focus section of this issue of the journal on 'Racial isolation and interaction in everyday life'. Taken together, the articles call for a reinterpretation of the spaces of contact in everyday life, with a new focus on the 'micro-ecology' of racialised divisions. Contributions are made in three areas: (a) meta-theory, with a turn to materiality, (b) new methodologies, and (c) understandings of racial segregation and contact. The contact hypothesis is reconsidered with new emphases on relations between bodies-space-time. A 'relational model' is given in efforts at explanation.
\end{abstract}

Keywords: bodies; contact; everyday life; micro-ecology; racism; segregation; space

The articles in this special focus section of the journal, namely of 'Racial isolation and interaction in everyday life' provide grounds for a further round of reflection regarding the current state of racialised interactions in a part of the world that has been only recently 'liberated' from centuries of various forms of institutional and legally enforceable racism. We should welcome the opportunity. We are more generally in a reflective mood having recent recall of 11 years of democracy, a third successful round of democractic elections and celebration of the fiftieth anniversary of the Freedom Charter which declared boldly in 1955 that 'South Africa belongs to all who live in it, black and white.'

The broad contours of the political transition are familiar to us: the new era announced in 1990 by de Klerk, the protracted negotiations, the euphoria of the first demoractic election in 1994, the 'rainbow nation', and the Constitution of 1996 based on principles of non-racialism but with a policy of redress (affirmative action) for previously disadvantaged persons along with women and persons with disabilities. We also passed through the Truth and Reconciliation Commission in the years 1996 to 2003, which yielded a weighty report of seven volumes. Racial laws have been 
repealed and an era of human rights has been opened up, supported by numerous state-sponsored commissions. Gateways to Africa have been chartered with the New Partnership for Africa's Development (NEPAD), the notion of an African Renaissance and the formation of the African Union. It is a very different place from that under apartheid rule.

Nevertheless, the centuries of racialised oppression and exploitation - slavery, colonial conquest, formal segregation, labour exploitation, apartheid and legalised racism - have left deep traces. Despite the tumbling of the formal racialised barriers and apparent equal opportunity for all, South Africa remains a decidedly unequal society. A recent local study (Brown \& Folscher, 2004) reported a national Ginicoefficient of between 0.68 and 0.73 (where 0 represents equality and 1 represents inequality) which means high inequality. Another study ranked South Africa in the 1990s as the fourth most unequal nation-state in the world (Morse, 2004). Economic inequalities are of course deeply racialised. Furthermore, the meso-level of segregation, the spatial distribution of housing and communities in cities and towns, remains relatively unchanged other than in limited areas. People differ sharply on all matters of public opinion across racialised divides. From this perspective it would appear that racialised isolation and separation is being reproduced. These are the issues and questions addressed by the articles in this special edition. Together, they form a kind of stock taking of where we are in racialised terms after eleven years of democracy.

Before proceeding, let us turn the clock back to the apartheid era. We need to be reminded first that apartheid was a large-scale endeavour at spatial engineering (literally millions of persons were forcibly removed to racialised 'group areas') and second, that apartheid involved an effort towards the total regulation of bodies and space at the micro sphere of human interaction; the notion of micro-segregation also known as petty-apartheid. As Foster and Finchilescu (1986) expressed it at that time, apartheid provided

[a] formidable battery of laws, regulations, proclamations and judicial interpretations that prescribe behaviour in a vast array of potentially inter-racial situations such as wedding, bedding, dining, entertaining, learning, praying, playing, defecating, voting, resisting, fighting, working; that is the medley of actions and activities that constitute a person's life (p. 122).

With the demise of apartheid, this sphere, the everyday spaces in which persons 'encounter one another in situations of bodily co-presence' (Dixon, Tredoux \& Clack, this issue, p. 395) is again opened for negotiation. How have these newly opened spaces been used? In an impressive series of studies on the public space of beaches in South Africa (Dixon \& Durrheim, 2003; Durrheim \& Dixon, 2004), the researchers found that despite quite complex swirls of patterning in space and through time sequences, racialised segregation remained the norm. The articles in this special focus section of this issue of the journal explore these matters - the micro-ecology of racial encounters - a bit further. They promise, in combination, to enhance our understanding and grasp of those notoriously persistent problems: racialisation and racism. 


\section{WHAT IS AT STAKE?}

There is perhaps more at stake in this collection of articles than readily meets the eye. Three main areas of questions are implicated: (a) questions about larger issues of theory or meta-theory, (b) questions about our understanding of racialisation and racism, and (c) matters pertaining to methodology.

First, the matter of meta-theoretical questions. The bigger picture here presents a useful challenge to the double Cartesian dualisms which have held a vice-like grip on much of mainstream social psychology. We refer of course to mind-body and individual-social dualisms; deep philosophical conundrums that have been played out over the course of Western modernity. Psychology has tended to favour the former over the latter; it prioritises minds over bodies and the individual over the social. Also at stake is a third form of enlightenment dualism: idealism-materialism. Psychology has experienced a variable history in this regard with behaviourism and neurological/biological accounts favouring a truncated instance of materialism, but in the long run, particularly with the rise of cognitivism, idealist versions have tended to dominate. This is what is at issue here. Expressed in a simplified form, the articles in this special focus section of the journal attempt to recover the muted 'others' of mainstream psychology: materiality of space, bodies as well as minds; and embodied persons-in-interaction rather than individuals in isolation. At stake is an engagement with neglected metatheoretical dimensions.

Second is the question of understanding and theorising racism and racialisation. To oversimplify the matter, psychology has, in general, tended to reduce the phenomenon from racism (a widespread ideology which serves to maintain relations of domination and oppression) to that of 'prejudice' (a personal attitude and faulty generalisation or stereotype) and then to locate the origin of prejudice inside the head of the individual, in the form of faulty cognitions, normal processes of categorisation and/or heuristics (mental shortcuts). Either we are all prone to prejudice due to the ubiquitous effects of categorisation (in which case racism and prejudice are inevitable) or only some people (the 'rotten apples') are prejudiced due to faulty cognition or damaged childhoods, and they should be the targets of intervention. Such approaches have been criticised, opponents arguing instead that racism and racialisation may be due to the dynamics of intergroup relations or alternatively to widespread discourses and representations about the 'other' (Foster, 1999). Yet other explanations have looked to large-scale macro-processes such as economic systems, political agendas or lengthy historical forms. While not wishing to eschew such understandings, the articles in this collection provide a shift of focus: racialisation also occurs in the micro-spaces of everyday bodily interactions. As Durrheim and Dixon (2004) rightly affirm, racial evaluation is an 'activity that people do together' (p. 632) in particular spatial configurations. Space is heavily implicated in persisting forms of oppression such as racialisation and patriarchy but we have only relatively recently become alerted to the importance of the spatial dimension (Foster, 1997, 2000). 
Space has been relatively neglected even in the metatheoretical shift that challenged mainstream psychology, social constructionism. In its quite justified turn to language in order to overcome the dualisms alluded to above (language after all is both action and idea, social and personal), constructionism itself has tended to become locked in with idealism to the relative neglect of the material. Rom Harré is one of the few constructionist theorists who has also regarded space and bodies as central. He has argued that identities should be regarded as an integrated system of locations in four interrelated manifolds: in space, in time trajectories, in a moral location and in social spaces, that is, a positioning in a structured order of people in terms of status and power arrangements (Harré, 1998; Harré \& Gillett, 1994). The very term positioning, which has become a significant conceptual tool in constructionism, itself is a spatial metaphor (Harré \& van Langenhove, 1999). There are no good reasons why spatial considerations should not be a central ingredient of constructionism. Space, after all, is both material and discursive.

A third issue at stake is the question of methodology. Just as the 'linguistic turn' opened up a whole range of new methods of analysis (discourse, narrative, conversation and rhetorical analysis), so too the more recent 'spatial turn' will require innovative approaches both to data collection and analysis. The early pioneers of studies into the everyday interactional order, Goffman $(1959,1974)$ and Garfinkel $(1967)$ had to acquire different ways of approaching their new subject matter. So too the present studies on the micro-ecology of spatial division. In this collection, the articles by Tredoux, Dixon, Underwood, Nuñez and Finchilescu, and Schrieff, Tredoux, Dixon and Finchilescu (this issue) offer commendable and innovative approaches to data collection and analysis in order to track and represent bodily configurations in space and in time. This does not imply that they entirely eschew the earlier methods. The article by Holtman, Louw, Tredoux and Carney in this issue uses standard methods to present very useful findings on the contact hypothesis.

\section{CONSIDERATIONS ON THE CONTACT HYPOTHESIS}

Emerging from studies of American soldiers in World War II (Stouffer et al., 1949), the contact hypothesis has been with us for a long time. It argues in two directions. On the one hand, it claims that a lack of contact has deleterious consequences; on the other, it hypothesises that contact, only under certain optimal conditions, could potentially have beneficial effects for both sides of antagonistic group relations. The details of this and the recent extensive literature reviews are addressed in the articles in this special focus section and need not be repeated here. The doctrine of apartheid was based on the reverse of the contact hypothesis, namely that "points of contact inevitably produce friction and friction generates heat which may lead to conflagration' (cited in Durrheim, this issue, p. 449). The aim was to cut contact between racialised categories to the absolute minimum; the outcome was very considerable human misery. Apartheid has been consigned to the rubbish bin of history. 
The first study on the contact hypothesis in South Africa was that of Russell (1961), in a study of an inter-racial neighbourhood in Durban, prior to the effects of the Group Areas Act. Two things can be said about this study. First, that contact produced positive relations between white, Indian and coloured people, contrary to the claims of the apartheid priesthood. Second, this interview-based study was based on the everyday micro-ecological approach being advocated here. It reports on everyday activities such as visiting homes, friendships and borrowings. It was aware of space and interactions-in-space. It could be suggested that we have been trying to recover these dimensions ever since.

At the height of the apartheid-era tensions and violence, the merits of the contact hypothesis in a 'non-contact' society were reviewed by Foster and Finchilescu (1986). They were pessimistic, arguing in effect that it would require a major transformation and restructuring of the macro-social order before contact per se could make an impact. Their conclusion may have been misinterpreted (see Holtman et al, this issue). Let us revisit their claim

It should be made plain that our argument is not that black-white contact may not contribute to positive effects ... a fully integrated society is unquestionably a cherished goal. The argument is rather that given the history and present nature of the South African problem, contact per se is not sufficient (Foster \& Finchilescu, 1986, p. 134).

The macro-political economic structure at that time precluded, for the most part, the kind of micro-ecological interactional forms that would meet the optimal conditions proposed by the contact hypothesis - status equality, common goals, co-operative interdependence and normative support. Contact was reported as 'contiguous yet utterly remote' (p. 125). Nevertheless, the upshot of this 1986 review meant that, as Dixon et al. (this issue) argue, the micro-ecology of racial division remained a neglected dimension.

Despite ongoing revisions, perhaps the greatest problem for the contact hypothesis has been its neglect of the spatial dimension (Dixon, 2001). Spatial dynamics tend either to be ignored or treated as inert background. But space is highly significant for human interaction; we interact rather differently in the 'spaces' of funerals and weddings. Various kinds of space either enable or constrain particular kinds of action. Places have specific meanings for people; they resonate with symbolic and emotional significance. We all carry with us various senses of 'place identity'. Spaces are anything but mere inert backdrops, as we may immediately recognise in 'home' and 'away' sporting records. When space is allowed to disappear so too do two other features integral to the analysis of space: bodies and temporal sequences. When bodily processes, space and temporal sequencing are faded into the background, then 'contact' just becomes an apparently neutral event, hollowed out from the very bodily practices which constitute it and which endow it with different meanings. 
It is to the credit of John Dixon and Kevin Durrheim in their significant beach contact studies that bodily practices, temporal sequencing, spatial manoeuvres and meaning are foregrounded and seen to swirl about in all their complexities. For them the notion of 'segregation' or 'desegregation' is the outcome of these bodily practices and space-time assemblages; a dynamic emergent. They open up the differential meanings of the micro-ecology of 'contact' (Durrheim \& Dixon, 2004). Whites tended to regard the contact as an 'invasion' of their previously privileged 'whitesonly' preserve (being pushed out of space), whereas black people, who welcomed the new opportunity for shared use of public space, saw whites as running away (white flight). The phenomenon of contact in this particular instance has different meanings for black and white participants (Durrheim, this issue). Meanings emerge from the body-space-time configurations. This is what is meant by the useful concept of the 'micro-ecology of racial division' (Dixon, Tredoux \& Clack, this issue). It is to the credit of these researchers that they open up new spaces and new methodologies for a reconsideration of what 'contact' may involve and mean.

Mindful of the disclaimer by Dixon et al. (this issue) that the micro-ecology is not entirely autonomous from macro-processes, we may ask whether there are any data on the broader picture of contact in South Africa. Fortunately there are. The Institute for Justice and Reconciliation conducted a national survey of 3498 respondents in mid-2003. Respondents were interviewed in the language of their choice by interviewers of the same 'race' as themselves. When asked how often they talked to people of other racial groups 'when socialising in your home or the home of friends', $46 \%$ answered never and 23\% said 'rarely' (an index of voluntary contact). When asked how often they talked to people of other racial groups 'on a typical day during the week, whether at work or otherwise', $26 \%$ of the total respondents answered 'never' and 24\% said 'rarely' (an index labelled as involuntary contact). For both indices, the reported results of little contact were highest for black and lowest for white respondents (see Lombard, 2003) - perhaps not particularly surprising when one considers the racial demographics and the continued de facto involuntary segregation of the townships and rural areas. Multiple inequalities and de facto spatial separation on a macro-scale appear to bedevil the opportunities for warm, open, equal encounters of the face-to-face voluntary variety. Only about $10 \%$ of respondents reported frequent ('always' or 'often') voluntary contact (Lombard, 2003). If such contact is regarded as the panacea, we have grounds indeed to be gloomy.

Whatever the final evaluation of the contact thesis, in the light of the reconsiderations expressed in this special focus section, the general issues raised by the 50something-year-old contact hypothesis will yet be around for some time to come. At least one of the current studies (see Holtman, Louw, Tredoux \& Carney, this issue) provides some grounds for optimism: contact was found consistently to be related to reduced measures of prejudice towards racialised 'others'. 


\section{FINDINGS OF THE PRESENT STUDIES}

As Dixon et al., (this issue) inform us, two of the studies presented here (Tredoux et al., this issue; Schrieff et al. this issue) are primarily descriptive, necessarily so, since there is relatively little work on micro-interactions. It is rather difficult to capture the micro-ecology of bodies-space-time woven together. To the credit of the researchers, they employed a mixture of observational and coding labour and new technologies (time-lag digital photography) along with custom-made computer aids to open up these interactional spaces and sequences. These innovative methods will be most useful for other researchers entering this relatively unexplored terrain. (Recall that interesting book on unobtrusive methods all those years ago. Well, unobtrusive methods have re-emerged again in these studies!)

What about the findings? Like the beach studies, this research also finds a substantial degree of voluntary racial segregation in an open public area within a university, and in residential dining rooms. On the public space of steps which look out over the whole Cape Peninsula, racially mixed groups were relatively scarce, 19\% in contrast to the $44 \%$ of gender mixed groups. The majority of those who used the steps were white and male, perhaps reflecting the standard assumptions of comfort in public places. In the dining-halls, informal racial segregation was evidenced in the general layout of the hall (left and right hand sides) and at specific tables. Clearly these findings, along with the beach contact studies, attest to the persistent salience of racialised identities. Racialised categories intertwine with spatial arrangements of bodies to create differential comfort-zone places. The next task for these researchers is to talk to these students in order to get an idea of the meaning of these bodily practices. It is perhaps not frivolous to remark that body-space practices readily become habitual and ritualised, and that everyday rituals reproduce the salience of racialised and gendered identities. For those who would hope for a comfortable non-racialism (most of these students would have been infants when Mandela was released from prison in 1990) in a democratic South Africa, these findings of persistent informal segregation are cause for concern.

In contrast, using more traditional methods and approaches, including self-report experiences of various levels of inter-racial contact, Holtman et al. (this issue) in a large and solid study involving 19 schools, present clear findings that contact was the most important predictor of racial attitudes and prejudice. The greater the selfreported contact experiences, the lower the measures of prejudice. Contact in this study was more important than socio-economic status, levels of integration of the schools or measures of racial identification. The classic contact hypothesis is alive and well; it reaffirms that long-held view that separation of spaces is not good for our being in relation to others. In this study we do not really get a handle on the nature of the meaning of the contact situation. Perhaps the researchers could dig into the selfreported measures of contact to give some flavour of the meaning of the encounter. In addition, there is room for further work of a qualitative sort, mapping the spaces of interaction in schools and the meaning of cross-racial encounters. 
Various articles in this section point to the significance of time in relation to space. As Dixon et al. (this issue) point out, a neglect of time runs the danger of 'freezing' what is rather a dynamic process of 'constantly becoming'. Neither boundaries, nor 'race' are pre-givens. They emerge, as do their meanings, out of particular body-space-time configurations or assemblages. This, of course, is in line with constructionist thinking and its attendant anti-essentialism. In such views, both integration and segregation are possibilities; they may coexist, in space-time sequences. That indeed is what Tredoux et al. (this issue) found: as space filled up on the steps, there was a decreasing segregation over time. The article by Durrheim (this issue) also gives attention to time in a number of ways. Recognition of historical time is important; it tells us that racialised (or gendered) interactions and representations are variable and changing; they have been and can be done in other ways. Then there are the more immediate spatio-temporal patterns; daily rhythms, hourly changes. At some times and places, beaches were more integrated, at other spaces and times, more segregated. This permits us to begin the difficult task of explanation. What underlies the emergent quality of segregation? Why is it so persistent, even after the laws are gone? How would we achieve a more integrated society? Difficult questions and ones not really fully answered in these articles. I will attempt to pull together some of the explanatory strands that are offered in order to try out a more integrated perspective.

\section{TOWARDS EXPLANATION}

Here are the explanatory strands in these articles. Finchilescu (this issue) puts forward the notion of meta-stereotypes and anxiety as a way of understanding the persistence of racial segregation. Meta-stereotypes refer to how we think or imagine that others view us. The experience of being stereotyped by others may raise anxieties in contact situations. In consequence, we may retreat to particular places of safety, away from the threat, 'comfort zones'; hence the reproduction of segregation. The advantage of this notion of meta-stereotyping lies, in line with other articles in this series, in its emphasis on the dyadic or the interactional dimension. It is not what is in one's head, but in how a person imagines others view her or him; it is interactional. But how do metastereotypes arise? Finchilescu gives some hints: the whole historical-political legacy of apartheid inequalities, socialisation, current ongoing spatial segregation, cultural differences, contemporary competition and rivalry for jobs (affirmative action).

In their article on dining-hall spaces, Schrieff et al. (this issue) raise the notion of space or place identity - the notion that people are more comfortable or secure in certain spaces rather than others - a kind of knowing one's place. They also invoke the notion of friendship patterns, implying that few cross-racial friendships were evident here. Both Durrheim (this issue) and Dixon et al. (this issue) suggest a dialectical view of the relationship between macro (historical-political legacies) and micro face-to-face interactions, local and global, practice and structure. However, they then locate primary explanation in the local, immediate set of body-space-time 
patterns, the micro-ecology of encounter. It is this zone of actual bodily practices that creates the emergent patterns of segregation or integration. The explanation lies not in some other reducible factors, but in what bodies do in relation to other bodies in that time-zone.

Drawing these explanatory strands together, I suggest a broader framework which could be called a 'relational model'. It claims, in concert with the authors cited above, the disarmingly simple notion that it matters how we inter-relate in bodily practice, in place-identity or in meta-stereotypic imagination to others. It relocates the explanatory base to the interactional sphere. Put more simply, it shifts away from the notion that we will find origins (or explanations) in the head (or body) of the individual, but rather in the constellation of relations between and among persons, groups, ideologies, spaces, time-sequences and juxtaposed positionings. It is in line with the social constructionist conception that what we take to be reality is constructed between us. We may of course disagree with that version of social reality, but disagreement is yet another kind of relational dynamic. Classical constructionism often takes the idea of the 'conversation' as its grounding metaphor (Shotter, 1993). While useful, it may be overly one-sided, favouring talk over bodies. Invoking Billig (1996) with his twosidedness, we may draw on the notion of 'micro-ecology' (Dixon et al., this issue) as a potential grounding metaphor for this 'relational model'. It tilts the balance to include the materiality of bodies-space-time in interaction. For a more detailed account of the 'relational model' as applied to political violence see Foster, Haupt and de Beer (2005).

What about race? Surely we know that 'race' is dead. It was killed off once by academics after World War II, then a second time with the advent of a democratic South Africa in 1994 - other than for purposes of redress, levelling the playing fields. If 'race' does not exist, how does it keep reappearing, as here in the form of persistent informal racial segregation? The 'relational model' suggests that it persists, because of the way that we relate to one another in the everyday interactions of bodies in space-time and conversations. As Durrheim (this issue) puts it, racial representations are grounded in spatio-temporal interactions and relational forms. Expressed starkly, if bodies sat higgledy-piggledy in dining-halls or university steps, if we could have conversations on equal terms, if we could 'do' micro-ecologies differently, then 'race' (the very idea) and its attendant forms of relating (segregation) would gradually disappear. It is quite possible.

If anything is rather missing from the collection of articles in this special focus section of this issue of the journal, it is this very question of the meaning of 'race' in contemporary times. In the main, we do not hear what respondents say about why they go about particular seating arrangements or in what ways people are racially different. From these studies we know that people continue to 'do' racialised subjectivities but we have less of a grasp of the meanings of blackness and whiteness in democratic South Africa. From the beach contact research (Durrheim, this issue) we do begin 
to gain some sense of racial meanings. Whites still carry a sense of entitlement to erstwhile 'whites-only' places, thus their sense of being displaced by desegregation. Blacks have a sense that whites still disparage them (meta-stereotypes at work) and that whites do not wish to share the new open dispensation. These voices begin to give us a sense of the meaning of 'race' eleven years after democracy. The implications? While it is important to collect data on bodies in space-time, it is equally important to hear voices and their interpretations of lived experience.

\section{CONCLUDING REMARKS}

The useful collection of six articles in this special focus section of this issue of the journal have made contributions to meta-theory, methodology, and more specifically to the understanding of contact and persistent segregation in democratic South Africa. They have presented challenges to the classical contact hypothesis in opening up the relatively neglected domain of the micro-ecology of racial encounters; a new recognition of the materiality of bodies in spatial-temporal practices and configurations. The most significant insight lies in the notion that it matters what bodies actually do in space and in temporal sequences. This does not displace the importance of voice and meaning posited by constructionism; it adds to it.

Can we hope for a future non-racialism in which the current salience of racialised subjectivity gradually disappears? The 'relational model' - a way of drawing together some strands of explanation - suggests that it depends on how we relate to one another in everyday encounters. When we change such habituated and ritualised action sequences we also change meanings and the very notion of 'race'. The contact hypothesis, long in the tooth as it is, still suggests the possiblity of positive social change.

\section{REFERENCES}

Billig, M. (1996). Arguing and thinking (rev. ed.). Cambridge: Cambridge University Press. Brown, S. and Folscher, A. (Eds). (2004). Taking power in the economy. Cape Town: Institute for Justice and Reconciliation.

Dixon, J. (2001). Contact and boundaries: 'Locating' the social psychology of intergroup relations. Theory and Psychology, 11, 587-608.

Dixon, J. and Durrheim, K. (2003). Contact and the ecology of racial division. British Journal of Social Psychology, 42, 1-23.

Durrheim, K. and Dixon, J. (2004). Attitudes in the fiber of everyday life. American Psychologist, 59, 626-636.

Foster, D. (1997). Space, place and race. Journal of Community and Health Sciences, 4, $1-10$.

-. (1999). Racism, Marxism, psychology. Theory and Psychology, 9, 331-352.

- (2000). Race, space and civil society. In J. Cochrane and B. Klein (Eds), Sameness and difference (pp. 57-78). Washington, D.C.: Council for Research in Values and Philosophy.

Foster, D. and Finchilescu, G. (1986). Contact in a 'non-contact' society. In M. Hewstone and 
R. Brown (Eds), Contact and conflict in intergroup encounters (pp. 119-136). Oxford: Blackwell.

Foster, D., Haupt, P. and de Beer, M. (2005). The theatre of violence. Cape Town: HSRC Press.

Garfinkel, H. (1967). Studies in ethnomethodology. Englewood Cliffs: Prentice-Hall.

Goffman, E. (1959). The presentation of self in everyday life. Harmondsworth: Penguin.

-. (1974). Frame analysis. New York: Harper.

Harré, R. (1998). The singular self. London: Sage.

Harré, R. and Gillett, G. (1994). The discursive mind. London: Sage.

Harré, R. and van Langenhove, L. (Eds) (1999). Positioning theory. Oxford: Blackwell.

Lombard, K. (2003). Half of South Africa: No contact with other races. Reconciliation Barometer, 1(4), 1-3.

Morse, S. (2004). Indices and indicators of development. London: Earthscan.

Russell, M. J. (1961). Study of a South African inter-racial neighbourhood. Durban: Institute for Social Research, University of Natal.

Shotter, J. (1993). Conversational realities. London: Sage.

Stouffer, S., Suchman, E., de Vinney, L., Star, S. and Williams, R. (1949). The American soldier. Princeton, N.J.: Princeton University Press. 